\title{
SISTEM INFORMASI PENGELOLAAN ARSIP SURAT DI KANTOR BPKAD PROVINSI NUSA TENGGARA BARAT BERBASIS WEB DENGAN PHP MYSQL
}

\author{
(Information System of Archive Letter Management in BPKAD West Nusa Tenggara \\ Province Based on PHP MYSQL)
}

\author{
Fifin Fajriani ${ }^{[1]}$, Andy Hidayat Jatmika ${ }^{[1]}$, Lalu Miftahul Ulum ${ }^{[2]}$ \\ ${ }^{[1]}$ Dept Informatics Engineering, Mataram University \\ Jl. Majapahit 62, Mataram, Lombok NTB, INDONESIA \\ ${ }^{[2]}$ UPTB Pelayanan Perbendaharaan Wilayah Pulau Lombok \\ BPKAD Provinsi NTB, Mataram, Lombok NTB, INDONESIA \\ Email : fifinfajriani.ff@gmail.com, andy@unram.ac.id, el.ulum82@gmail.com
}

\begin{abstract}
Abstrak
Perkembangan terknologi komputer dan sistem informasi pada saat ini telah mengalami peningkatan yang sangat pesat, dimana hal ini sejalan dengan kebutuhan masyarakat terhadap informasi. Masyarakat saat ini cenderung cepat dalam mengikuti arus perkembangan teknologi, menuntut adanya ketersediaan informasi yang cepat, tepat dan akurat. Badan Pengelolaan Keuangan dan Aset Daerah Provinsi (BPKAD) Nusa Tenggara Barat adalah suatu badan/institusi pemerintahan yang merupakan gabungan dari sub Bagian Perlengkapan pada Biro Umum Sekretariat Daerah (Setda) Provinsi Nusa Tenggara Barat dan eks Biro Keuangan Setda Provinsi Nusa Tenggara Barat. Pada penulisan ini akan membahas mengenai pengembangan sistem informasi pengelolaan arsip surat yang bertujuan untuk mempermudah pegawai instansi dalam mengetahui data-data pada pengarsipan maka dibuatlah sebuah sistem yaitu "Sistem Informasi Pengelolaan Arsip Surat di Kantor Pemerintahan BPKAD Provinsi Nusa Tenggara Barat Berbasis Web dengan PHP MySQL”. Berdasarkan sistem yang dibuat untuk membantu kinerja para pegawai instansi, didapatkan hasil pengujian sistem pada responden yang merupakan pegawai BPKAD yaitu sebesar $92 \%$ responden setuju dengan sistem yang dibuat.
\end{abstract}

Keywords: Perkembangan Teknologi, Sistem Informasi, Pengarsipan, PHP, MySQL.

\section{Pendahuluan}

Perkembangan terknologi komputer dan sistem informasi pada saat ini telah mengalami peningkatan yang sangat pesat, dimana hal ini sejalan dengan kebutuhan masyarakat terhadap informasi. Masyarakat saat ini cenderung cepat dalam mengikuti arus perkembangan teknologi, menuntut adanya ketersediaan informasi yang cepat, tepat dan akurat. Setiap instansi baik instansi pemerintahan maupun swasta pasti membutuhkan sistem informasi yang mampu menunjang kinerjanya untuk mendapatkan serta menghasilkan informasi dengan cara yang lebih efektif dan efisien.

Badan Pengelolaan Keuangan dan Aset Daerah Provinsi (BPKAD) Nusa Tenggara Barat adalah suatu badan/institusi pemerintahan yang merupakan gabungan dari sub Bagian Perlengkapan pada Biro Umum Sekretariat Daerah (Setda) Provinsi Nusa Tenggara Barat dan eks Biro Keuangan Setda Provinsi Nusa Tenggara Barat. BPKAD Provinsi Nusa Tenggara Barat bertugas untuk memudahkan dalam menyelesaikan permasalahan aset maupun keuangan yang kompleks untuk diserahkan kepada Pemerintah Provinsi yang dimana data diperoleh dari tiap-tiap Kabupaten/Kota yang ada di Provinsi Nusa Tenggara Barat.

BPKAD Provinsi Nusa Tenggara Barat didukung oleh sumber daya manusia sebanyak 146 orang dalam menjalankan tugasnya. Untuk bagian arsip sendiri tidak dikelola oleh semua pegawai melainkan dikelola oleh beberapa staff saja dengan satu orang sebagai kepala pimpinan yang mengelola surat secara keseluruhan. Pelaporan segala jenis arsip surat dari tahun ke tahun masih dilakukan secara manual dengan menginputkan data informasi surat dengan menggunakan Microsoft excel, dimana untuk melakukan pendataan informasi laporan mengenai segala arsip pun hanya dapat dilakukan pelaporan secara keseluruhan yang mana hal tersebut seharusnya dapat dilakukan secara lebih efektif dan efisien. Hal yang dapat dilakukan untuk mempermudah pegawai dalam membuat laporan pendataan arsip surat yaitu dengan cara menambahkan rentang tanggal pencetakan laporan yang ingin diketahui informasi datanya secara lebih detail.

Maka dari itu, berdasarkan uraian dan analisa yang telah dilakukan, dalam rangka pengabdian kepada masyarakat, penulis akan membuat sebuah sistem informasi yang dapat melakukan pengelolaan arsip surat berbasis web dengan menggunakan Bahasa PHP guna menyajikan data-data secara lengkap dan efisien yang 
diharapkan mampu membantu pihak Kantor BPKAD Provinsi Nusa Tenggara Barat dalam melakukan pengelolaan terhadap arsip surat. adalah :

Tujuan dari pembuatan sistem informasi pengelolaan arsip surat di kantor BPKAD Nusa Tenggara Barat ini

1) Untuk merancang dan membangun sebuah sistem informasi pengelolaan arsip surat untuk kantor BPKAD Provinsi Nusa Tenggara Barat yang berbasis web.

2) Untuk membantu pegawai dalan melakukan pengelolaan arsip surat yang lebih efektif dan efisien serta mempermudah dalam pendataan surat-surat yang ada.

3) Untuk mempermudah pegawai dalam melakukan pengecekan perihal pengkonfirmasian surat yang dapat dilihat secara langsung pada sistem.

Manfaat dari pembuatan sistem informasi pengelolaan arsip surat di kantor BPKAD Provinsi Nusa Tenggara Barat ini adalah sebagai berikut :

4) Memudahkan pegawai BPKAD Provinsi Nusa Tenggara Barat untuk melakukan pengelolaan arsip surat dengan cara yang lebih sederhana serta transparan bagi seluruh pegawai.

5) Efisiensi dan efektifitas dalam melakukan pengelolaan arsip surat oleh pegawai kantor BPKAD Provinsi Nusa Tenggara Barat.

\section{TinjaUAn Pustaka}

\subsection{Sistem Informasi}

Sistem adalah bagian-bagian yang saling berkaitan yang beroperasi bersama untuk mencapai beberapa sasaran atau maksud. Secara garis besar ada dua kelompok pendekatan sistem, yaitu Pendekatan sistem yang lebih menekankan pada elemen-elemen atau kelompoknya didefinisikan sebagai Suatu jaringan kerja dari prosedurprosedur yang saling berhubungan, berkumpul bersama-sama untuk melakukan suatu kegiatan atau menyelesaikan suatu aturan tertentu. Menurut Davis, G.B, sistem secara fisik adalah kumpulan dari elemen-elemen yang beroperasi bersama-sama untuk menyelesaikan suatu sasaran [1].

Sistem informasi adalah kumpulan dari subsistem apapun baik fisik ataupun non-fisik yang saling berhubungan satu sama lain dan bekerja sama secara harmonis untuk mencapai satu tujuan yaitu mengolah data menjadi informasi yang memiliki arti dan berguna [2].

\subsection{Database/Basis Data}

Database adalah kumpulan field - field yang mempunyai kaitan antara satu file dengan field yang lain sehingga membentuk bangunan data untuk menginformasikan kondisi lalu lintas dalam bahasa tertentu. Basis data adalah kumpulan file - file yang saling berelasi, relasi tersebut biasa ditunjukan dengan kunci dari tiap file yang ada. Satu basis data menunjukkan kumpulan data yang dipakai dalam satu lingkup informasi. Dalam satu file terdapat record - record yang sejenis, sama besar, sama bentuk, merupakan satu kumpulan entity yang seragam [3].

\subsection{Aplikasi Berbasis Web dan Web Server}

Web merupakan kumpulan halaman- halaman yang digunakan untuk menampilkan informasi,gambar gerak, suara, dan atau gabungan dari semuanya itu baik yang bersifat statis maupun dinamis yang membentuk satu rangkaian bangunan yang saling terkait dimana masing-masing dihubungkan dengan link-link. Di dalamnya mengunakan protokol HTTP (hypetext transfer protocol) dan untuk mengaksesnya menggunakan perangkat lunak yang disebut browser [4].

\subsection{Perancangan Sistem}

Tahap perancangan sistem menghasilkan gambaran rancang bangun sistem informasi pengelolaan arsip surat di kantor pemerintahan BPKAD Provinsi Nusa Tenggara Barat. Pengambaran basis data akan menggunakan bentuk Entity Relationship Diagram (ERD), sedangkan untuk gambaran sistem akan menggunakan Unified Modeling Languange (UML) [5].

\subsubsection{Class Diagram}

Class diagram merupakan hubungan antar kelas dan penjelasan detail tiap-tiap kelas di dalam model desain dari suatu sistem, juga memperlihatkan aturan-aturan dan tanggung jawab entitas yang menentukan perilaku sistem.

\subsubsection{Use Case Diagram}

Use case diagram merupakan pemodelan untuk kelakuan (behavior) sistem informasi yang akan dibuat. Use case digunakan untuk mengetahui fungsi apa saja yang ada di dalam sistem informasi dan siapa saja yang berhak 
menggunakan fungsi-fungsi tersebut. Seorang atau sebuah aktor adalah sebuah entitas manusia atau mesin yang berinteraksi dengan sistem untuk melakukan pekerjaan-pekerjaan tertentu [6].

\subsubsection{Activity Diagram}

Activity diagram menggambarkan workflow (aliran kerja) atau aktivitas dari sebuah sistem atau proses bisnis. Diagram ini sangat mirip dengan flowchart karena memodelkan workflow dari satu aktivitas ke aktivitas lainnya. Pembuatan activity pada awal pemodelan proses dapat membantu memahami keseluruhan proses.

\subsubsection{Entity Relationship Diagram (ERD)}

ERD merupakan model yang menjelaskan hubungan antar data dalam database berdasarkan objek - objek dasar data [7]. ERD (Entity Relation Diagram) juga dapat dikatakan sebagai sebuah diagram yang digunakan untuk merancang hubungan antar tabel-tabel dalam basis data [8]. ERD (Entity Relation Diagram) berguna untuk menggambarkan gambaran dari dunia nyata yang akan diterapkan pada suatu database sebuah sistem.

\subsection{MySQL}

MySQL adalah sebuah basis data yang mengandung satu atau jumlah tabel. Tabel terdiri atas sejumlah baris dan setiap baris mengandung satu atau sejumlah tabel. Tabel terdiri atas sejumlah baris dan setiap baris mengandung satu atau sejumlah tabel. Tipe data MySQL adalah data yang terdapat dalam sebuah tabel berupa field - field yang berisi nilai dari data tersebut. Nilai data dalam field memiliki tipe sendiri - sendiri [9].

\subsection{XAMPP}

XAMPP adalah perangkat lunak bebas, yang mendukung banyak sistem operasi, merupakan kompilasi dari beberapa program. Fungsinya adalah sebagai server yang berdiri sendiri (localhost), yang terdiri atas program Apache HTTP Server, MySQL database, dan penerjemah bahasa yang ditulis dengan bahasa pemrograman PHP dan Perl. Nama XAMPP merupakan singkatan dari X (empat sistem operasi apapun), Apache, MySQL, PHP dan Perl. Program ini tersedia dalam GNU General Public License dan bebas, merupakan web server yang mudah digunakan yang dapat melayani tampilan halaman web yang dinamis [10].

\section{Metode Pengabdian MASyarakat}

\subsection{Metode Perancangan Sistem}

Pengembangan perangkat lunak Rancang Bangun Sistem Informasi Pengelolaan Arsip Surat di Kantor Pemerintahan BPKAD Provinsi Nusa Tenggara Barat menggunakan model waterfall. Model waterfall adalah model klasik yang bersifat sistematis, berurutan dalam membangun software. Model ini melakukan pendekatan secara sistematis dan berurutan. Model waterfall atau yang sering disebut model classic life cycle menunjukkan pengembangan perangkat lunak secara berurutan dan sistematis dimulai dari tahap analisis kebutuhan sistem lalu menuju ke tahap analisis, desain, coding, testing/verification, dan maintenance. Alur kerja dari model waterfall dapat dilihat pada Gambar 1.

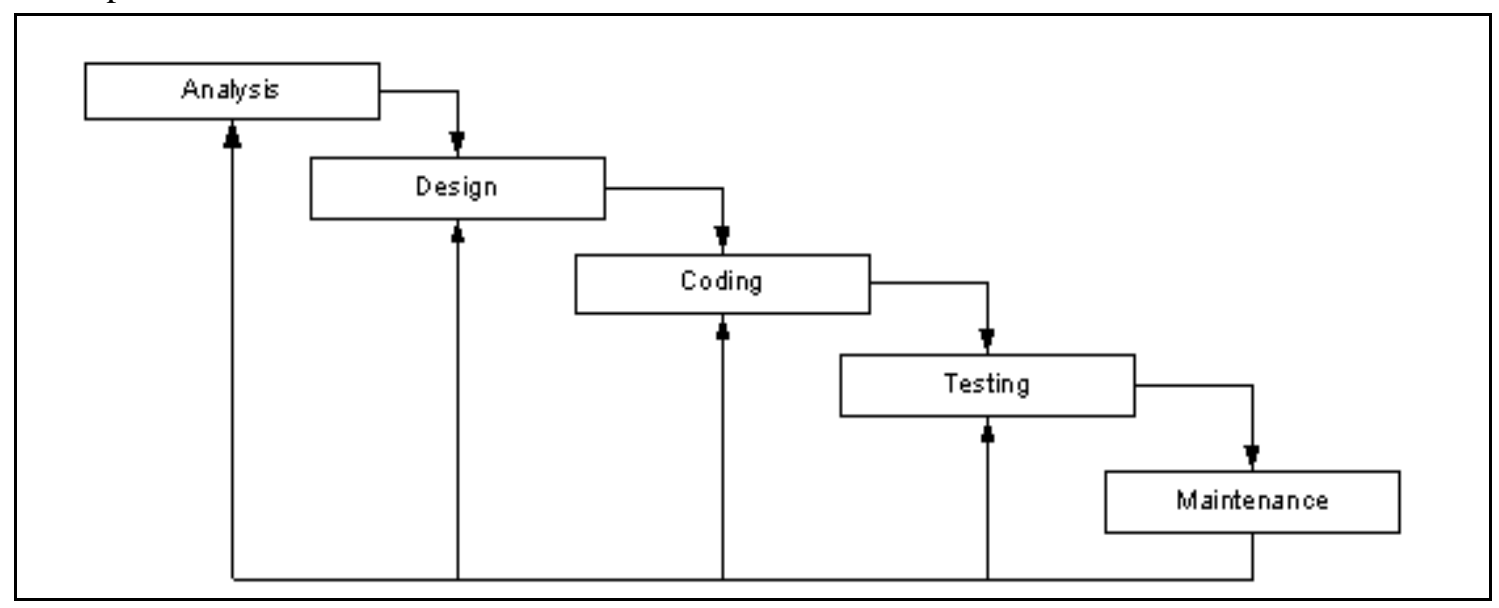

Gambar 1. Metode Penelitian Waterfall 


\subsection{Desain Sistem}

Pada Rancang Bangun Sistem Informasi Pengelolaan Arsip Surat di Kantor Pemerintahan BPKAD Provinsi Nusa Tenggara Barat ini terdapat empat diagram yaitu Use Case Diagram, Activity Diagram, Class Diagram, dan Entity Relationship Diagram, berikut penjelasannya pada subbab dibawah.

\subsubsection{Use Case Diagram}

Gambar 2 merupakan use case diagram dari Rancang Bangun Sistem Informasi Pengelolaan Arsip Surat di Kantor Pemerintahan BPKAD Provinsi Nusa Tenggara Barat. Terdapat dua user yaitu admin dan pegawai yang akan menggunakan sistem ini.

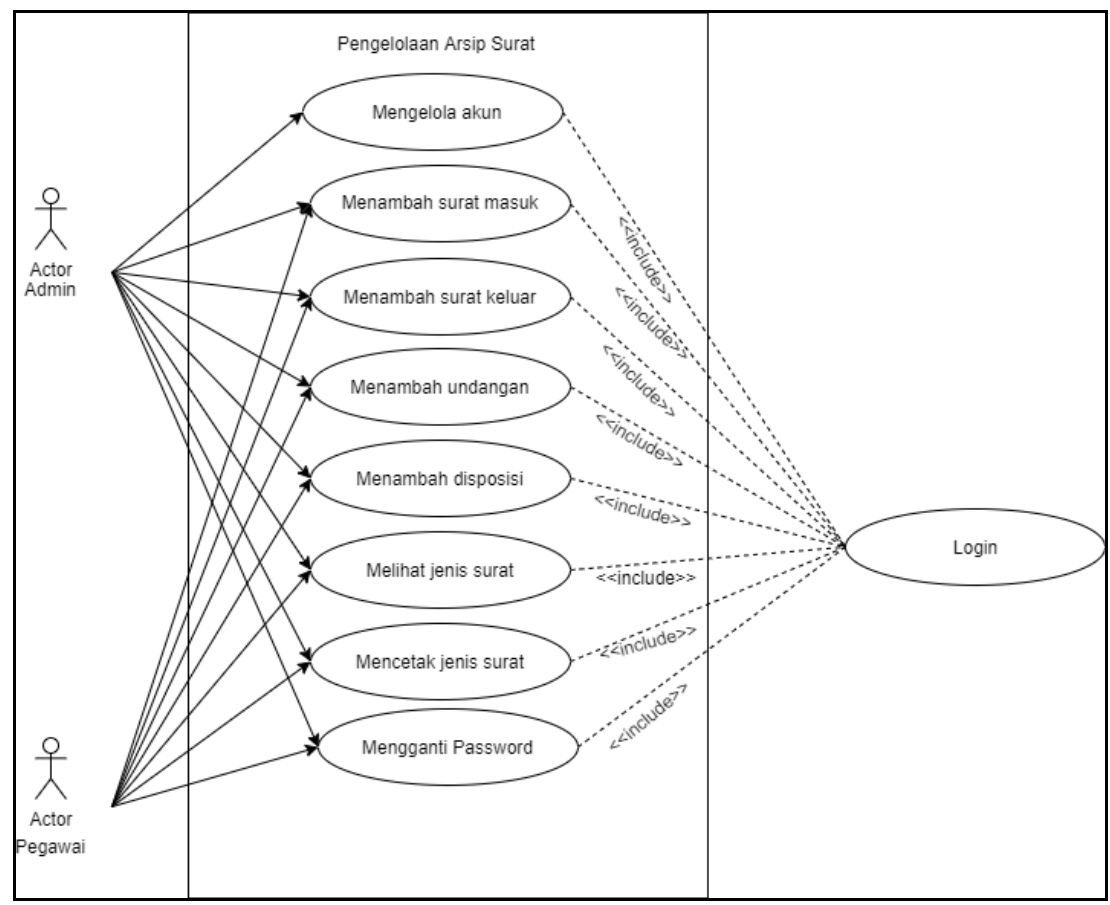

Gambar 2. Use Case Diagram

\subsubsection{Activity Diagram}

Activity diagram pada Rancang Bangun Sistem Informasi Pengelolaan Arsip Surat di Kantor Pemerintahan BPKAD Provinsi Nusa Tenggara Barat ini digunakan untuk menggambarkan semua proses yang ada pada sistem informasi ini. Berikut adalah activity diagram dari seluruh proses yang ada pada Rancang Bangun Sistem Informasi Sistem Informasi Pengelolaan Arsip Surat di Kantor Pemerintahan BPKAD Provinsi Nusa Tenggara Barat. Berikut merupakan Activity Diagram dari sistem informasi pengelolaan arsip surat.

a. Proses Login.

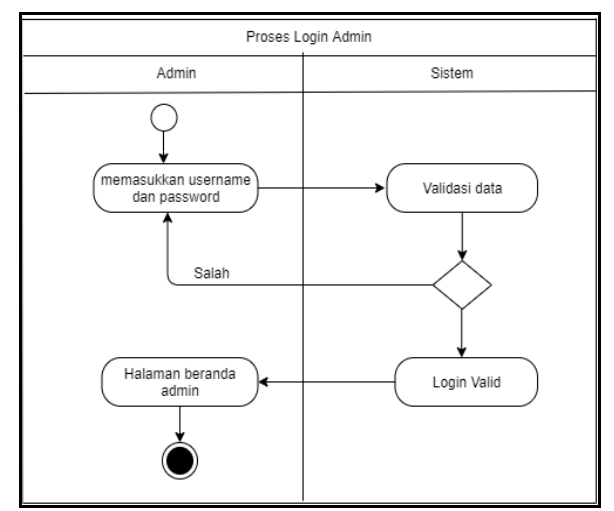

Gambar 3. Activity Diagram

Pada Gambar 3 di atas menggambarkan aktivitas admin untuk masuk ke dalam sistem melalui proses login. 
b. Proses Input Data.

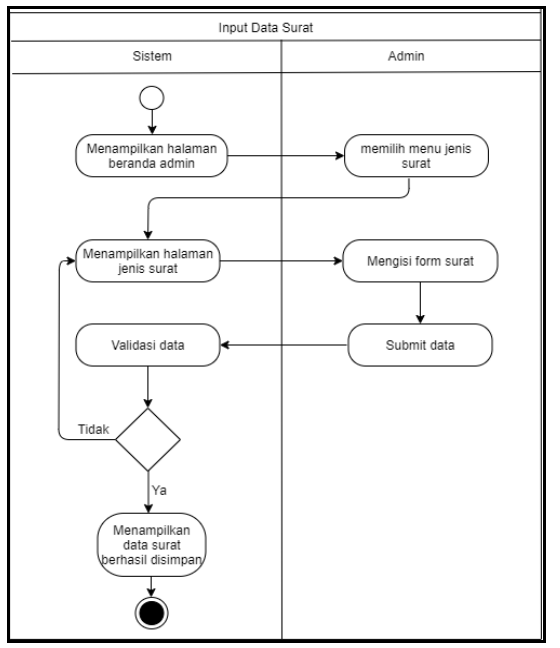

Gambar 4. Activity Diagram Proses Input Data

Seperti yang dapat dilihat pada Gambar 4.4 di atas telah dijelaskan aktivitas untuk melakukan penginputan data surat.

c. Proses Hapus Data.

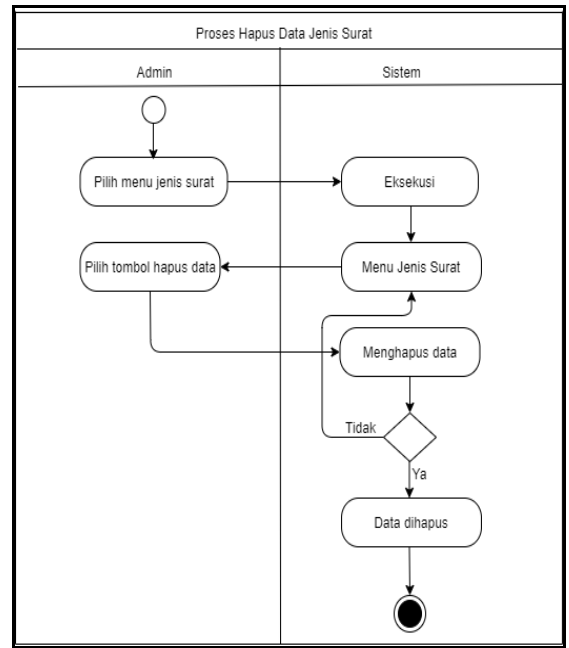

Gambar 5. Activity Diagram Proses Hapus Data

Gambar 5 di atas menjelaskan aktivitas untuk melakukan proses menghapus data surat yang telah terdaftar dalam sistem.

d. Proses Update Data. 


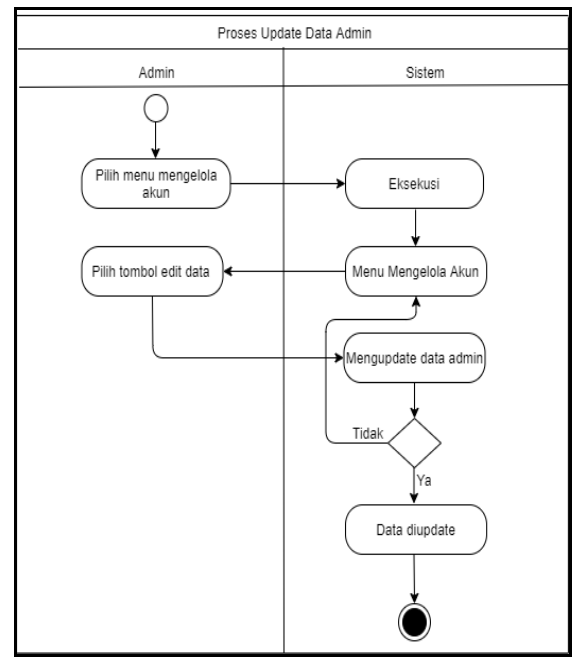

Gambar 6. Activity Diagram Proses Update Data

Pada sistem informasi pengelolaan arsip surat ini, admin dapat melakukan proses peng-updatean data. Dilihat pada Gambar 6 di atas telah menjelaskan aktivitas untuk melakukan peng-updatean data.

e. Proses Mencetak Surat.

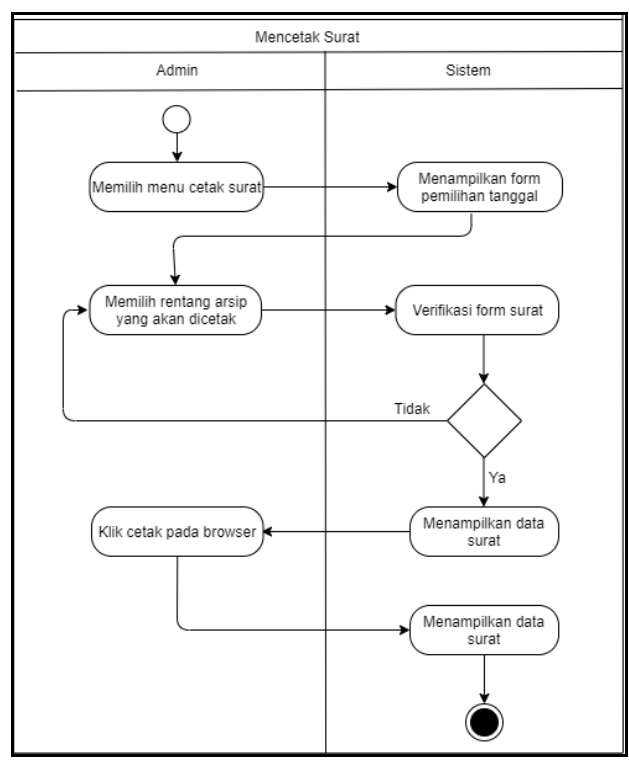

Gambar 7. Activity Diagram Proses Mencetak Surat

Pada sistem informasi pengelolaan arsip surat ini, kedua user dapat melakukan pencetakan terhadap data-data dari arsip surat. Gambar 7 menjelaskan aktivitas untuk melakukan pencetakan data-data dari arsip surat pada sistem informasi pengelolaan arsip surat ini.

\subsubsection{Class Diagram}

Class Diagram pada Gambar 12 telah menggambarkan hubungan antara relasi dari setiap kelas yang ada pada Rancang Bangun Sistem Informasi Pengelolaan Arsip Surat di Kantor Pemerintahan BPKAD Provinsi Nusa Tenggara Barat. 


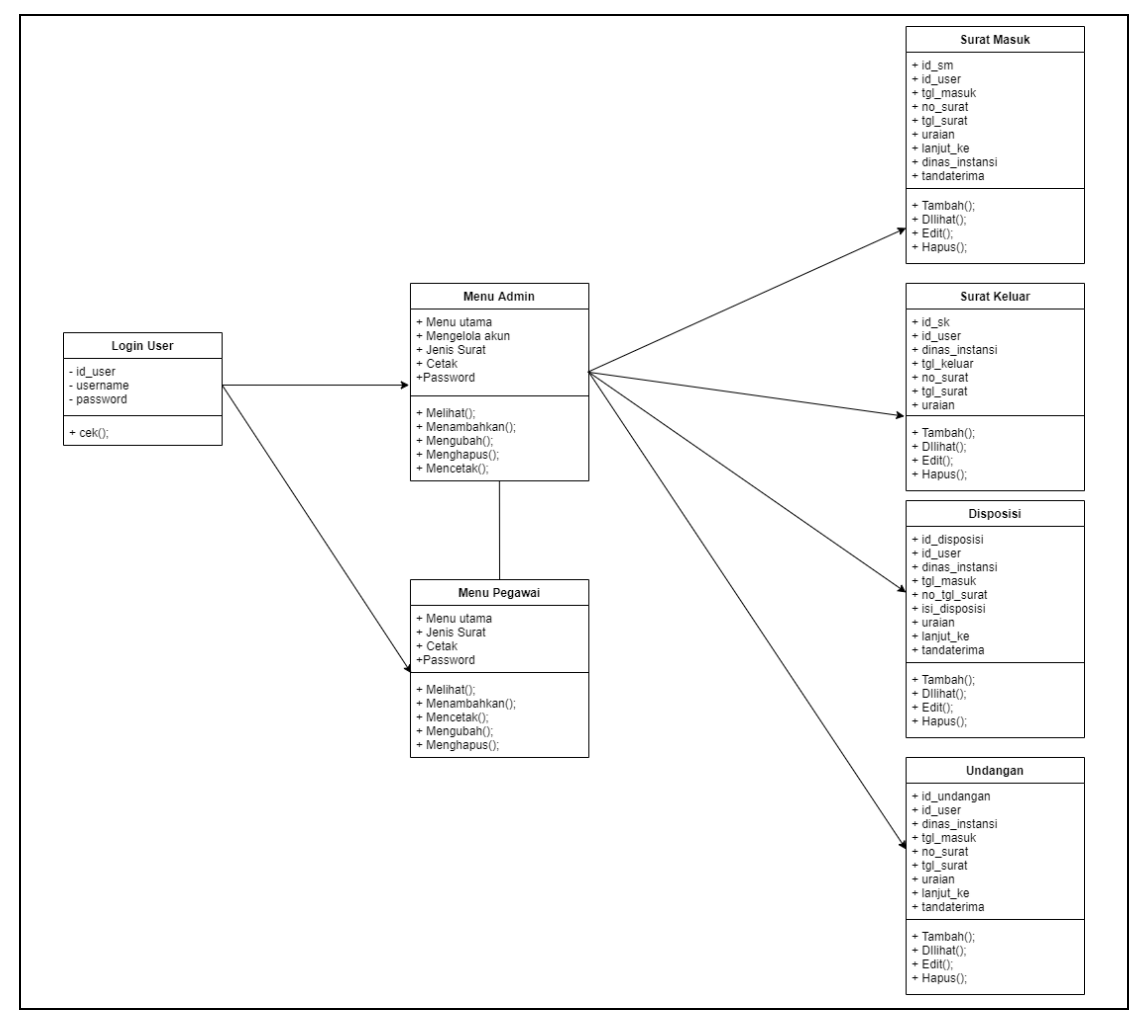

\subsubsection{Entity Realitionship Diagram}

Gambar 8. Class Diagram

Pada Gambar 13 berikut dapat dilihat ERD (Entity Relationship Diagram) dari Rancang Bangun Sistem Informasi Pengelolaan Arsip Surat di Kantor Pemerintahan BPKAD Provinsi Nusa Tenggara Barat.

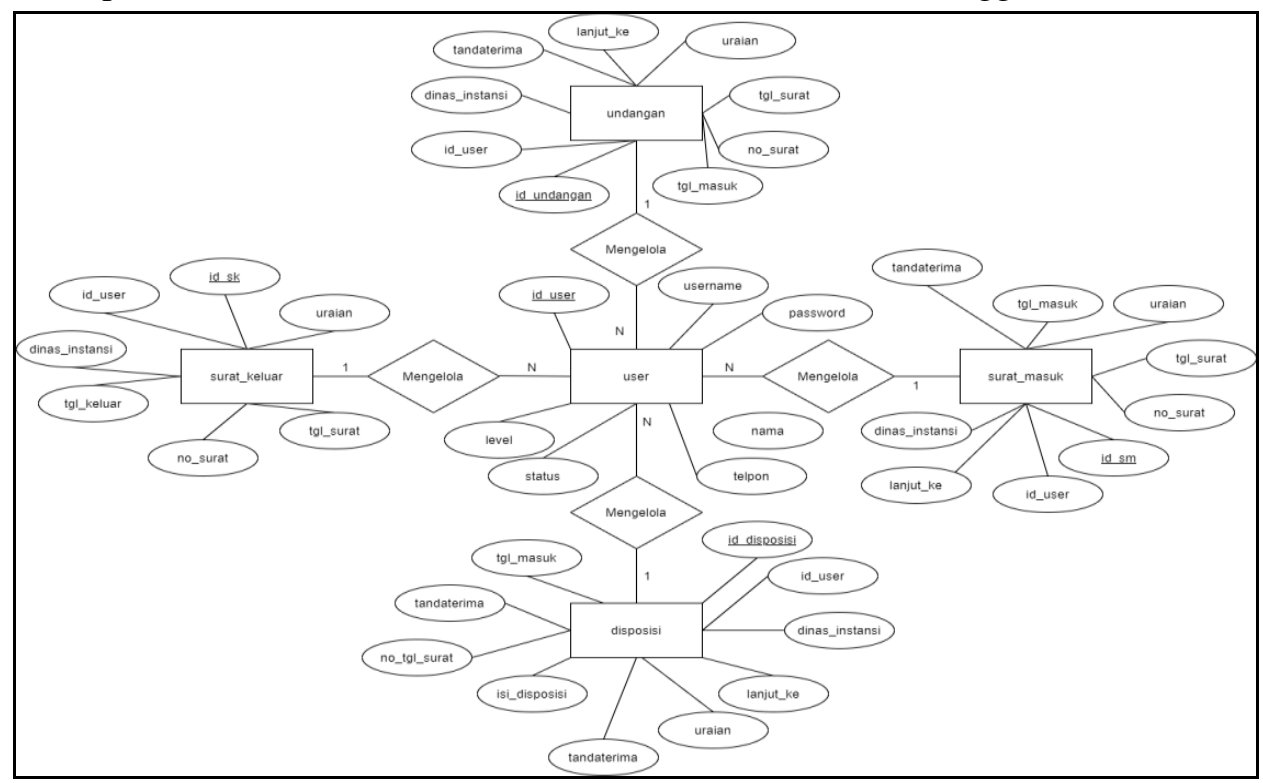

Gambar 9. Entity Realitionship Diagram

\section{HaSil dan PEMbahasan}

\subsection{Implementasi Sistem}

Berikut adalah implementasi tampilan (interface) program dari Rancang Bangun Sistem Informasi Pengelolaan Arsip Surat di Kantor Pemerintahan BPKAD Provinsi Nusa Tenggara Barat. 
a. Halaman Login.

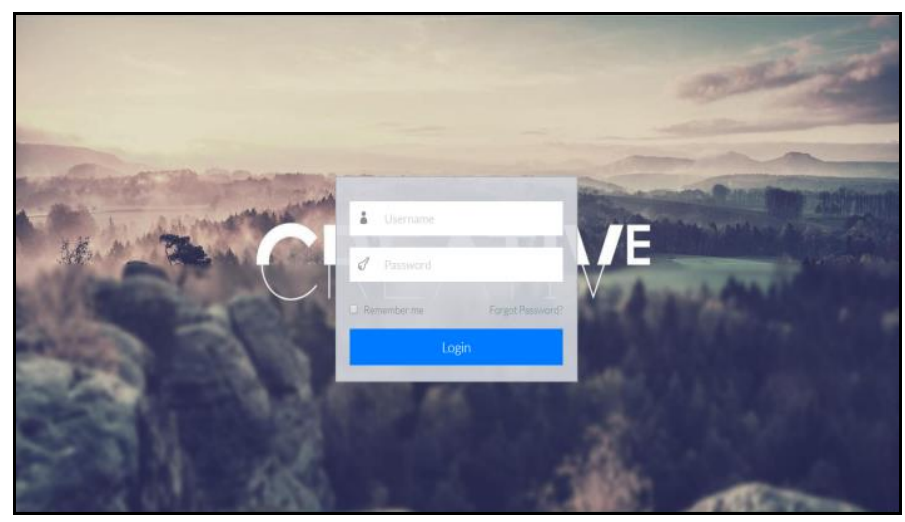

Gambar 10. Halaman Login

Pada Gambar 10 di atas merupakan interface dari halaman login untuk user admin ataupun pegawai.

b. Halaman Utama/Beranda.

Gambar 11 berikut merupakan interface dari halaman utama/beranda untuk user admin. Halaman ini muncul ketika user telah melakukan login pada sistem.

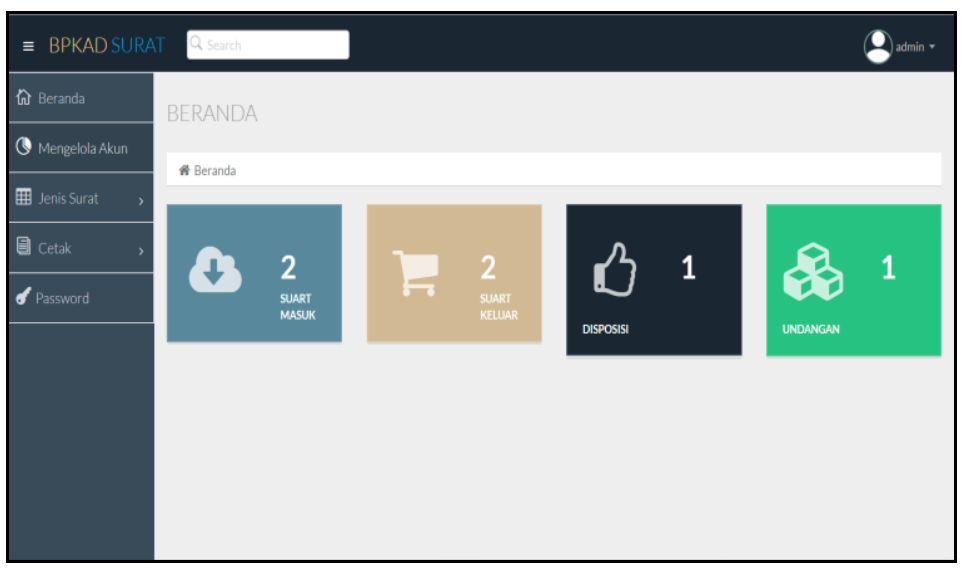

Gambar 11. Halaman Utama/Beranda

c. Halaman Mengelola Akun.

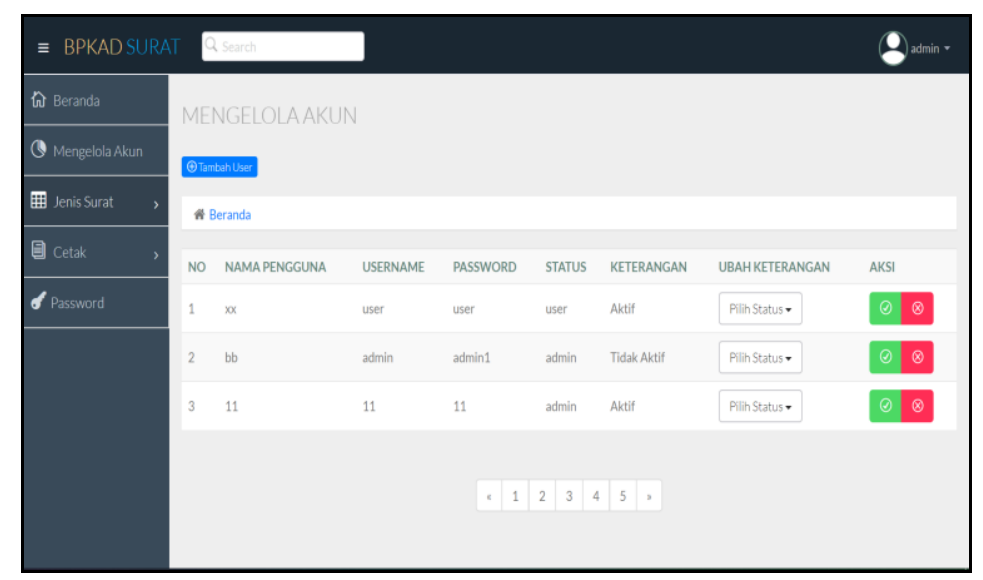

Gambar 12. Halaman Mengelola Akun 
Gambar 12 di atas merupakan tampilan untuk halaman mengelola akun yang dapat diakses hanya oleh admin saja. Pada halaman ini admin dapat melakukan perubahan data untuk para pegawai.

d. Halaman Jenis Surat.

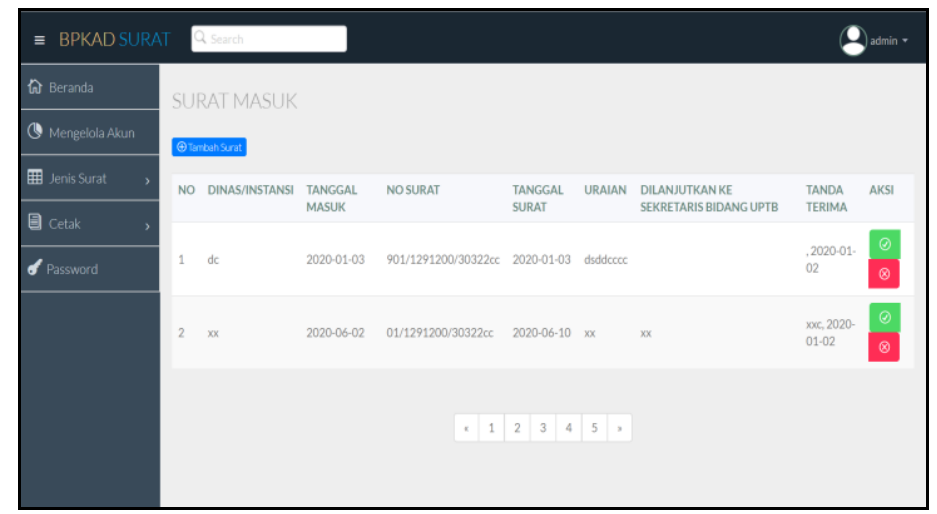

Gambar 13. Halaman Jenis Surat

Pada Gambar 13 di atas terdapat tampilan dari halaman surat masuk untuk admin maupun pegawai. Pada halaman ini terlihat bahwa user dapat menambahkan data jenis surat, mengedit, dan dapat menghapus data surat yang telah terdaftar sebelumnya.

e. Halaman Tambah Jenis Surat.

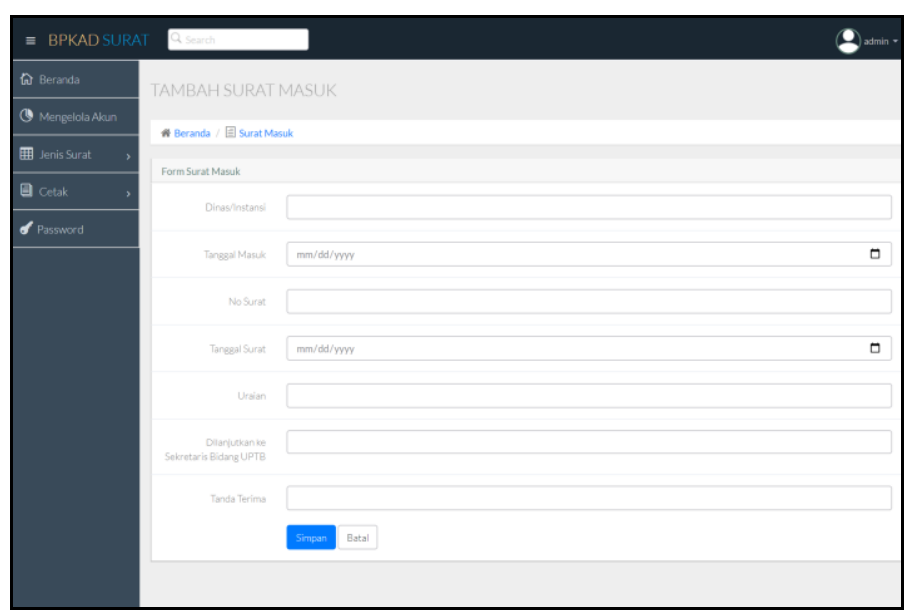

Gambar 14. Halaman Tambah Jenis Surat

Pada Gambar 14 di atas terdapat tampilan dari halaman tambah surat masuk untuk kedua user. Pada halaman ini terlihat bahwa kedua user dapat meng-inputkan informasi yang dimiliki oleh masingmasing jenis surat.

f. Halaman Cetak Jenis Surat. 


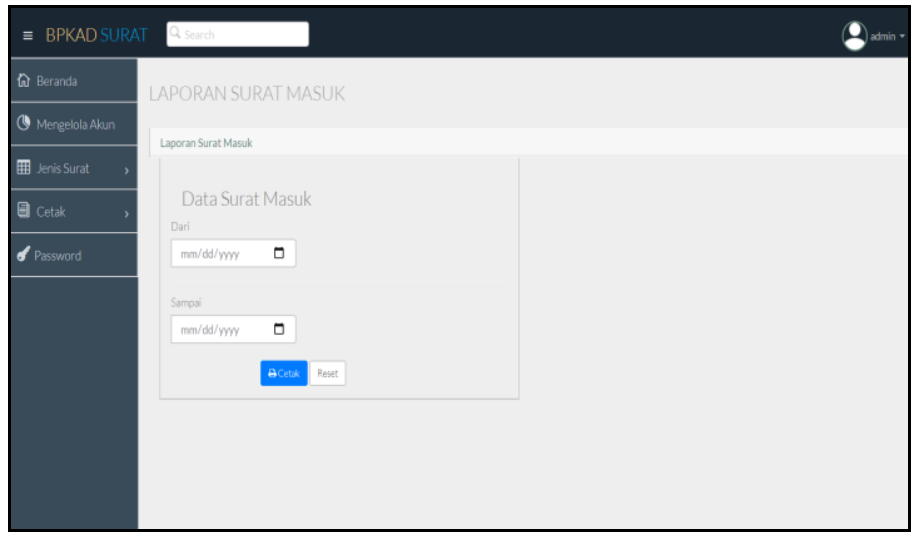

Gambar 15. Halaman Cetak Jenis Surat

Gambar 15 di atas merupakan tampilan dari halaman cetak, dimana pada menu cetak untuk masing masing surat terdapat tampilan yang sama baik untuk jenis suratnya maupun untuk usernya sendiri yaitu admin dan pegawai.

\subsection{Pengujian Kuesioner Pegawai}

Setelah dilakukan proses pengimplementasian sistem tahap selanjutnya pada pengabdian masyarakat yang dilakukan adalah pengujian sistem di lingkungan instansi tempat praktek kerja lapangan berlangsung yaitu kantor BPKAD Provinsi Nusa Tenggara Barat. Pengujian sistem dilakukan dengan melakukan uji coba sistem lalu memberikan responden yang merupakan pegawai BPKAD Provinsi Nusa Tenggara Barat yang telah melakukan uji coba sistem sebuah kuesioner untuk dijawab berdasarkan uji kelayakan sistem.

Dari pertanyaan - pertanyaan yang ada pada kuesioner responden, diberikan opsi atau pilihan jawaban sebagai berikut :
a. SS
$=$ Sangat Setuju
b. $\mathrm{S}$
$=$ Setuju
c. $\mathrm{C}$
= Cukup
d. TS
$=$ Tidak Setuju
e. $\quad$ STS
$=$ Sangat Tidak Setuju

TABEL 1. HASIL PENGISIAN KUESIONER OLEH PEGAWAI

\begin{tabular}{|l|l|c|c|c|c|c|}
\hline \multirow{2}{*}{ No } & \multicolumn{1}{|c|}{ Pernyataan } & \multicolumn{5}{c|}{ Pilihan Jawaban } \\
\cline { 2 - 7 } 1. & $\begin{array}{l}\text { SS } \\
\text { Sistem sudah baik dan mudah } \\
\text { digunakan. }\end{array}$ & 3 & 2 & 0 & 0 & 0 \\
\hline 2. & $\begin{array}{l}\text { Sistem mempermudah kerjaan } \\
\text { pegawai. }\end{array}$ & 2 & 3 & 0 & 0 & 0 \\
\hline 3. & $\begin{array}{l}\text { Pengelolaan data pada sistem } \\
\text { akurat. }\end{array}$ & 2 & 3 & 0 & 0 & 0 \\
\hline 4. & $\begin{array}{l}\text { Sistem menunjang kinerja } \\
\text { pegawai. }\end{array}$ & 3 & 2 & 0 & 0 & 0 \\
\hline 5. & $\begin{array}{l}\text { Sudah sesuai dengan kebutuhan } \\
\text { instansi. }\end{array}$ & 4 & 1 & 0 & 0 & 0 \\
\hline \multicolumn{1}{|c|}{ Total } & 14 & 11 & 0 & 0 & 0 \\
\hline \multicolumn{1}{|c|}{ Rata - rata (\%) } & 56 & 44 & 0 & 0 & 0 \\
\hline
\end{tabular}


Berdasarkan hasil pengujian kuesioner mengenai uji kelayakan Sistem Informasi Pengelolaan Arsip Surat di kantor Pemerintahan BPKAD Provinsi Nusa Tenggara Barat yang telah dilakukan, maka diperoleh hasil keseluruhan dari pernyataan responden yaitu berjumlah 25 poin yan terdiri di SS (Sangat Setuju) berjumlah 14 poin yang berpersentase $56 \%$ dan S (Setuju) berjumlah 11 poin yang berpersentase $44 \%$. Hasil tersebut diperoleh dari 5 orang responden. Maka dapat disimpulkan bahwa sistem ini sangat berguna untuk membantu para pegawai kantor BPKAD Provinsi Nusa Tenggara Barat.

\section{KESIMPULAN DAN SARAN}

\subsection{Kesimpulan}

Berdasarkan hasil pengabdian masyarakat yang dilakukan di bagian Sub-bagian Program Kantor Badan Pengelolaan Keuangan dan Aset Daerah Provinsi Nusa Tenggara Barat berupa Perancangan dan Pembangunan Sistem Informasi Pengelolaan Arsip Surat di Kantor Pemerintahan BPKAD Provinsi Nusa Tenggara Barat berbasis web, maka dapat disimpulkan beberapa hal sebagai berikut :

a. Rancang Bangun Sistem Informasi Pengelolaan Arsip Surat di Kantor Pemerintahan BPKAD Provinsi Nusa Tenggara Barat berbasis web ini dibuat dengan baik dan mudah digunakan oleh para pegawai. Sesuai hasil dari kuesioner hasil pengujian sistem yang telah diisi oleh pihak dari BPKAD Provinsi Nusa Tenggara Barat dengan persentase jawaban sebesar $92 \%$. Sistem ini juga mempermudah kerja pegawai dengan persentase jawaban sebesar $88 \%$.

b. Pada proses pengujian sistem oleh pegawai untuk pengelolaan data pada sistem akurat diperloeh nilai $88 \%$ berdasarkan hasil dari kuesioner yang telah dijawab oleh pegawai kantor BPKAD Provinsi Nusa Tenggara Barat.

c. Unuk uji kelayakan sistem mengenai kesesuaian sistem terhadap kebutuhan instansi memiliki persentase berdasarkan kuesioner yang telah dijawab oleh pegawai kantor BPKAD Provinsi Nusa Tenggara Barat sebesar 92\%. Serta kelayakan sistem dalam menunjang kinerja pegawai memperoleh persentase nilai sebesar $96 \%$.

\subsection{Saran}

Adapun saran yang dapat diberikan penulis agar Rancang Bangun Sistem Informasi Pengelolaan Arsip Surat di Kantor Pemerintahan BPKAD Provinsi Nusa Tenggara Barat ini menjadi lebih baik di masa yang akan datang, agar dalam pengembangan kedepannya sistem informasi ini juga dapat diperbaharui lahi dalam hal hal tampilan dan terutama fitur/fungsinya agar bisa ditambahkan.

\section{DAFTAR PUSTAKa}

[1] J. Hutahaean, Konsep Sistem Informasi, ed.1. Sleman: deepublish, 2015. 19-20.

[2] Gata, Windu dan Gata, Grace. 2013. Sukses Membangun Aplikasi Penjualan dengan Java. Jakarta : Elex Media Komputindo.

[3] Soepomo, P. (2014). Perancangan Sistem Informasi Inventory Spare Part Elektronik Berbasis Web Php (Studi CV. Human Global Service YOGYAKARTA). 2(2), 534-543.

[4] Arief, M.Rudyanto. 2011. Pemrograman Web Dinamis Menggunakan PHP \& MySQL. Yogyakarta: Andi.S. Priyo, D. Cahyadi dan Z. Arifin, "Sistem Informasi Sebaran Penjualan Kendaraan Bermotor Roda 2 di Kalimantan Timur Berbasis Web," Jurnal Informatika Mulawarman, vol.11 ,no.1, hal. 2-3, Tahun 2016.

[5] Iskandar, A. P. S., \& Supartha, I. K. D. G. (2019). Sistem Informasi Geografis Pemetaan Sebaran Alumni: Sistem Informasi Geografis Pemetaan Sebaran Alumni Pada STMIK STIKOM Indonesia. Journal of Computer Science and Informatics Engineering (J-Cosine), 3(2), 172-180.

[6] E. A. K. Lestari, S. E. Anjarwani, N. Agitha, "https://jcosine.if.unram.ac.id," Vol.2 No.1:Juni 2018. Available : https://doi.org/10.29303/jcosine.v2i1.68.

[7] Sumiati, S. E. Anjarwani dan M. A. Albar, "Rancang Bangun Sistem Informasi Pengelolaan Surat dan Kearsipan pada Sekertariat Daerah Provinsi NTB berbasis WEB," J-COSINE, vol.2 ,no.1 E-ISSN:2541-0806, hal. 9-11, Tahun 2018.

[8] Prijambodo. 2018. Out of The Box Koperasi tantangan perubahan kini dan masa depan. Yogyakarta: Ahmed Ghoseen A.

[9] Y. Kustiyahningsih, D. Rosa. 2011. Pemrograman Basis Data Berbasis WEB Menggunakan PHP dan Mysl. Yogyakarta : Graha Ilmu.

[10] B. Raharjo,I. Heryanto, E.Rosdiana K. Modul Pemograman Web HTML, PHP \& MySQL. Bandung : Modula, 2010.C. A. Pamungkas, Pengantar dan Imlementasi Basis data, Sleman: deepublish, 2017. 15-35. 